\title{
O curso de pedagogia em Cuba: um estudo voltado para os valores morais na educação infantil.
}

\author{
The pedagogy course in Cuba: a study aimed for \\ moral values in early childhood education.
}

Drielly Adrean Batista ${ }^{1}$

Alonso Bezerra Carvalho²

\section{Resumo}

O presente trabalho aborda a formação dos professores em Cuba, destacando a importância dos valores morais na educação infantil, de forma a considerar alguns aspectos, como: a formação dos docentes de Pedagogia, a estrutura pedagógica, a organização curricular e o perfil do formador. Considera-se não somente o intelectual, mas um conjunto formado pelos aspectos afetivo, moral e emocional, que mediam a aprendizagem e levam o aluno a pensar, por meio da prática, a construção dos aspectos teóricos. Este trabalho busca, assim, empreender uma reflexão acerca da formação dos docentes em Cuba. O desenvolvimento moral é um processo contínuo, interativo e dinâmico que tem início quando a criança nasce e perdura por toda a vida, apresentando características diferentes em cada período do desenvolvimento do ciclo vital. Esse desenvolvimento depende, sobretudo, da interação do indivíduo com o meio e das experiências morais proporcionadas pelos diferentes aparelhos sociais. Finalmente, esperamos ter contribuído para o desenvolvimento de um novo olhar sobre a educação, de maneira a estimular uma reflexão sobre aspectos importantes no que diz respeito à realidade na formação dos professores no Brasil.

Palavras-Chave: Educação. Professores. Cuba. Valores Morais.

\begin{abstract}
The present work deals with the training of teachers in Cuba, highlighting the importance of moral values in early childhood education, in order to consider

1 Graduada em Pedagogia e Letras (Português e Espanhol) com especialização em Psicopedagogia Clínica e Institucional, Mestre em Psicologia pela Universidade Estadual Paulista UNESP Assis, Doutoranda em Educação pela Universidade Estadual Paulista UNESP Marília e Membro do Grupo de Estudo e Pesquisa em Educação, Ética e Educação (GEPEES), cadastrado no CNPq. E-mail: driellyadrean@yahoo.com.br.

2 Doutor em Filosofia da Educação e Livre-Docente em Didática. Atualmente é professor do Departamento da Educação na Unesp/Assis e do Programa de Pós-Graduação em Educação da Unesp/Marília. Líder do Grupo de Estudo e Pesquisa em Educação, Ética e Educação (GEPEES), cadastrado no CNPq. E-mail: alonso.carvalho@unesp.br.
\end{abstract}


some aspects, such as: teacher education, pedagogical structure, curricular organization and teacher profile. It is considered not only the intellectual, but a set formed by the affective, moral and emotional aspects that mediate learning and lead the student to think through practice, the construction of theoretical aspects. This work seeks to undertake a reflection on the training of teachers in Cuba. Moral development is a continuous, interactive and dynamic process that begins when a child is born and endures throughout life, presenting different characteristics in each period of development of the life cycle. This development depends, above all, on the interaction of the individual with the environment and the moral experiences provided by the different social apparatuses. Finally, we hope to have contributed to the development of a new perspective on education, in order to stimulate a reflection on important aspects regarding the reality in the training of teachers in Brazil.

Keywords: Education. Teachers. Cuba. Moral Values.

\section{Introdução e História do curso de Pedagogia em Cuba}

A formação de professores, cuja base é o ensino universitário, tem sido um assunto muito importante nos dias atuais.

Cuba é uma referência quando se fala sobre a formação de professores, sua estrutura curricular, a organização dos cursos de licenciatura e a prática docente.

Cuba está localizada na parte insular da América Central. Região conhecida como Antilhas. O arquipélago é formado por mais de 1600 ilhas e ilhotas, com aproximadamente 105 mil km² de extensão. Por estar na entrada do golfo do México, o arquipélago fica próximo da América do Norte, mais precisamente dos Estados Unidos da América, do mar do Caribe e da Jamaica, e também do Haiti. (OLIVEIRA, 2007, p. 41):

Em Cuba, de acordo com a $\mathrm{OEI}^{3}$ (Organização dos Estados Iberoamericanos) há dois tipos de Órgãos de Estado: os Órgãos superiores de Poder Popular e os Órgãos Locais de Poder Popular.

De acordo com Hernández (1995), há os Órgãos Superiores do Poder Popular, como uma Assembleia Nacional, juntamente com os Conselhos de

\footnotetext{
${ }^{3}$ A OEI é um organismo internacional de caráter governamental cujo objetivo é a cooperação entre os países ibero-americanos nos campos da educação, da ciência, da tecnologia e da cultura, dentro do contexto do desenvolvimento integral da democracia e da integração regional.
} 
Estado e o Conselho de Ministros. Já a Assembleia do Poder Popular é formada pelo poder do Estado, mas está voltada para a fala e para as opiniões do povo. Esses órgãos são renovados a cada 5 anos, em sessões ordinárias, as quais ocorrem duas vezes ao ano. Os Ministros encarregados de dirigir a Educação do País são o Ministerio de Educación e o Ministerio de Educación Superior. Entre esses Ministérios há uma grande relação politica com a Educação, juntamente com o Ministerio de Cultura, a Academia de Ciencias de Cuba e o Instituto Nacional de Desportes y Recreacion.

Segundo a divisão político-administrativa do País descrita por Hernández et al. (1995, cap. 1), Cuba compreende 14 províncias e 169 municipios, entre os quais se destaca a Ilha da Juventude.

Cuba deixou de ser uma colônia da Espanha em 1898, mas foi governada por muitos anos pelos Estados Unidos da América, que administrou a Ilha durante aproximadamente sessenta anos.

$\mathrm{Na}$ década de 1950, de acordo com Hernández (1995), havia aproximadamente meio milhão de analfabetos. Somente metade da população era atendida no ensino primário. Os ensinos médio e universitário eram oferecidos somente nas grandes cidades da Ilha. O ensino industrial, o qual podia ser comparado ao técnico no nível médio, voltava-se para as grandes empresas da época e seu objetivo era a formação de mão de obra barata. Havia 16 centros de formação, dirigido aos operários e caracterizado por uma qualificação pequena e de baixa qualidade. Ainda que Cuba fosse um país voltado para a área agrícola, o ensino industrial era reduzido. As escolas normais totalizavam somente $6 \mathrm{em}$ toda a Ilha e serviam para a formação de professores. E o número de universidades para formar os profissionais da Educação era apenas 3: a Universidade de La Havana, a Las Villas e a Oriente. Havia também o fato de essas instituições de ensino superior terem poucas vagas disponiveis; além disso, ocorriam muitas fraudes na obtenção das vagas (HERNANDEZ, 1995, p. 3).

Os dados encontrados referem-se ao período compreendido entre 1957 e 1958. Além disso, abarcam somente os dois últimos anos do governo de Fulgêncio Batista. A proposta orçamentária para a educação era de apenas 
O curso de pedagogia em Cuba...

79,4 milhões de pesos cubanos (CUP), o que correspondia a 11 pesos por pessoa, isto é, a um valor quase insignificante. Após o triunfo da Revolução e a queda do governo de Fulgêncio Batista, o governo começou a investir na educação, a fim de resolver os problemas passados, com uma proposta de diminuição da taxa de analfabetismo, garantindo o oferecimento de educação para todos.

Muitas leis e decretos foram elaborados com o objetivo de proporcionar excelência ao ensino e às propostas de governo. Algumas das leis consideradas importantes para o marco do Sistema Educacional Cubano foram as seguintes: a Lei 561 , de 15 de setembro de 1959, que visava à criação de 10.000 salas de aulas para a escola básica; e a Lei 680, de 23 de dezembro de 1959, que estabelecia mudanças na educação. Na Lei 561, estabeleciam-se os níveis de ensino, como seriam os centros para a formação básica, a obrigatoriedade do ensino até os 12 anos ( $6^{\text {a }}$ série), a criação do ensino secundário (6 ${ }^{\text {a }}$ a $9^{\mathrm{a}}$ série) e o ensino pré-universitário (HERNANDEZ, 1995). A ampliação do acesso às escolas foi acontecendo rapidamente, e a população mostrava-se motivada. No entanto, para atender toda a demanda do País, foi necessária a atuação de muitos professores, e, como o acesso à universidade era restrito, foram indispensáveis mudanças também no ensino universitário.

Para Hernandez (1995), houve por parte da população muito esforço e incentivo às reformas na educação e na alfabetização. Os números relativos à educação aumentavam a cada ano e chegaram a 707.212 mil alfabetizados, o que levou o índice de analfabetismo a uma redução de 23,6 \% para 3,9 \%, de acordo com o censo de 1981.

A Lei da Nacionalização da Educação foi firmada em junho de 1961 e estipulou que a educação fosse pública e gratuita para todos. Além disso, essa lei determinou que o Estado e outros departamentos sempre estariam à frente de toda a organização educacional.

Em 1961, aproximadamente dois anos após o triunfo da Revolução, começaram a surgir os Círculos Infantis, que atendiam crianças de 0 a 5 anos e garantiam a educação e o cuidado dessas crianças, juntamente com o atendimento às mães. Anteriormente esses Círculos eram chamados de 
creches (guarderias), lugares que proporcionavam apenas o cuidado com as crianças, sem nenhuma preocupação com a aprendizagem e o desenvolvimento infantil. Essas "creches" foram transformadas em instituições pedagógicas, onde o cuidar e o desenvolvimento intelectual, afetivo, cognitivo, social e moral funcionavam como uma ponte entre o cuidar e o ensinar. No começo do ano de 1962, a Reforma da Educação Superior foi aprovada, e os serviços relacionados à educação e à pesquisa foram todos regulamentados.

Entre o final da década de 1960 e o início dos anos 1970, as escolas destinadas à formação de professores foram criadas e transformadas, hoje, nas Faculdades dos Institutos Superiores Pedagógicos, voltados para a formação de licenciados em Educação Primária. De acordo com Hernández (1995), esse projeto levou a uma grande expansão da classe escolar, produzindo mudanças na descentralização da docência.

Portanto, foi a partir da Revolução de 1959 que se começou a modificar, no País, a situação precária relacionada ao analfabetismo e à falta de professores. No século XXI, houve um favorecimento à erradicação do analfabetismo e à universalização da educação. Essa erradicação resultou em altos índices de notas elevadas dos alunos, de acordo com a Organização das Nações Unidas para a Educação (Unesco). Todo o contexto educacional cubano está centrado na universalização do ensino público e gratuito, visando à qualidade da educação e da formação dos docentes. Esse modelo educacional compreende tanto o Ensino Infantil quanto o Superior.

En un inicio, estos centros de formación de maestros (escuelas de formación de maestros primarios que sustituyeron a las antiguas Escuelas Normales de Maestros) estuvieron en las montañas, después, la Revolución creó escuelas de formación de maestros en cada provincia, a las que se ingresaba con la educación primaria culminada y, más adelante, cuando las condiciones de desarrollo lo propiciaron, en nivel de ingreso fue con la secundaria básica terminada [...] A partir de 1976, los institutos superiores pedagógicos construídos como centros universitários independientes, conformaron una rede de instituicones dirigida a la 
O curso de pedagogia em Cuba...

cobertura de docentes para lograr la universalización hasta el nivel medio y superior. (GÓMEZ GUTIERREZ, 2006, p. 6-7)

O aparato educacional de Cuba é todo fundamentado no Sistema Nacional Unificado. Esse sistema funciona muito bem, em virtude da pequena extensão territorial do País. Conforme se mostrou no início deste trabalho, Cuba é um arquipélago formado por duas ilhas, habitadas por cerca de 11 milhões de pessoas.

O sistema educacional cubano se apóia [sic] nos princípios de carássivo da educação; no princípio da vinculação estudo da educação; no princípio da participação de toda a sociedade nas tarefas da educação do povo; da coeducação [sic] e no princípio da gratuidade do ensino em todos os níveis. (FREITAS, 1998, p. 2016)

A estrutura do ensino é organizada da seguinte maneira: Círculo Infantil (zero a quatro anos de idade); Pré-escolar (cinco anos), Escola Primária (6 a 11 anos); Secundária Básica (12 a 14 anos); Pré-universitária; Escolas de Ofícios, Secundária, Obrero-campesina e Instituto Politécnico (15 a 17 anos); Universidades e Centros Universitários e Institutos Superiores. Para os alunos que não conseguem atingir o nível superior, há o chamado "Programa de Superação".

A organização do governo, voltada para o ensino unificado, é constituída por oito ministérios, um escritório, um comitê e um instituto nacional. O Ministério da Educação Superior é o responsável pelas faculdades de formação que atuam na área educacional.

A formação de professores em Cuba, desde a Educação Infantil ao Ensino Universitário, é constituída por cursos de licenciatura plena de nível superior, os quais estão sob total responsabilidade do Estado. Todos os cursos de licenciatura são de período integral, têm duração de 5 anos e uma ampla ligação entre a universidade e a escola (teoria e prática). Outro aspecto relevante do curso de Pedagogia em Cuba é o diagnóstico integral do aluno 
que está iniciando o curso de licenciatura, por meio da qualificação de cada perfil do discente.

A formação do professor requer: um desenvolvimento do pensamento reflexivo e da autonomia; orientação da motivação para aprender; capacidade para resolver conflitos e integração dos processos de interação do individual com o coletivo, bem como uma efetiva relação entre os conteúdos e a prática social.

O currículo do curso de Pedagogia está organizado, primeiramente, pelo caráter teórico intensivo, com o objetivo de trabalhar aspectos psicológicos, pedagógicos e sociológicos. No segundo ano, os estudantes já são encaminhados às escolas denominadas "microuniversidades", que são sedes universitárias criadas para atender os alunos de Pedagogia. Nesse momento os alunos (futuros professores) trabalham com seus tutores pensando em grupo e socializando com sua equipe. Isso estabelece, desde cedo, uma relação entre prática e pesquisa. "En la escuela tiene lugar la interacción de los maestros que se forman con los docentes de experiencia ya en ejercicio"(MARIÑO SÁNCHEZ et al., 2004, p. 6-9).

Dessa maneira, após um ano de estudos teóricos intensivos, empreende-se uma formação voltada para a prática, e os alunos são orientados e assessorados pelos professores tutores das sedes universitárias municipais. Esse funcionamento da formação dos professores dá-se mediante o programa "Universalización de la Educación Superior", cuja meta é inserir todos na educação superior em 10 anos.

O ensino superior cubano está regido pelo plano de universalização da educação superior, que foi implantado em 2003 e cujo objetivo é abranger toda a população. O governo garante cursos superiores a todos os estudantes que concluam o Ensino Secundário Pré-universitário e sejam aprovados no exame de ingresso.

Os professores universitários do curso de Pedagogia recebem uma formação pedagógica na própria instituição em que atuam. Durante essa formação, os docentes são preparados para lecionar no mencionado curso e para colocar em prática os saberes a eles transmitidos, tendo sempre em 
O curso de pedagogia em Cuba...

mente que o objetivo da Educação Superior cubana, nos cursos de licenciaturas que formam professores, é articular a teoria com a prática desde o principio.

O Instituto Central de Ciências Pedagógicas (ICCP), criado em 1976, começou a ter um papel importante na Ciência da Educação (Pedagogia e Didática) em toda a Ilha. Em 2011, aconteceu o primeiro Congresso Internacional de Pedagogia em Cuba, com a finalidade de divulgar para o mundo a Educação Cubana e o modelo que a inspira. A esse Congresso compareceram representantes de vários órgãos do mundo, unindo povos e olhares diferentes com a intenção de investigar a Educação Cubana.

“Universidade para Todos" e "Mesa Redonda" são projetos que ampliam a relação do cidadão cubano com os assuntos das políticas educacionais internacional e nacional. O período que vai de 2005 a 2010 enfocou a “educação à altura de seu tempo" Nesse período, realizou-se um esforço para enriquecer o sistema nacional de educação e colocá-lo em concordância com as exigências do atual momento.

Em 2006, a Orealc, ${ }^{4}$ juntamente com a Unesco, declararam Cuba como exemplo de excelência na educação. Esses órgãos consideraram que o alto desempenho cubano em termos de educação se deve à qualidade na formação dos professores. De acordo com Castro (1999), que aborda a formação dos professores em Cuba:

Os professores cubanos são contratados por 40 a 44 horas por semana e espera-se que ensinem de 16 a 20. São reservadas, portanto, 20 horas para preparar as aulas e interagir com os alunos. As salas de professores estão disponiveis para estas atividades extra-classe. Espera-se que, de fato, os professores permaneçam às 40 horas na escola. E o que é mais importante para qualidade do ensino, boa parte da preparação das aulas e materiais pedagógicos é feita em regime colegiado. De fato, é permitido que dediquem um dia por semana para seu aperfeiçoamento profissional. $\mathrm{Na}$ escola secundária visitada, todos os 59 professores tinham feito cursos de pós graduação. Além da possibilidade de alocar parte das

\footnotetext{
${ }^{4}$ Orealc é a sigla da Oficina Regional da Educação para América Latina y el Caribe. Exerce uma missão de conhecimento da educação, juntamente com os direitos humanos durante toda sua existência.
} 
40 horas para o estudo, os cursos de pós graduação conduzem a um adicional de salários, criando um grande incentivo para continuar os estudos (CASTRO, 1999, p. 344).

Para atingir a mencionada excelência no ensino, desenvolvem-se e preveem-se programas educativos e sociais de curto e de longo prazos, a fim de eliminar as barreiras que reprimem aspirações e para aumentar as oportunidades e as possibilidades de cada criança, adolescente, jovem e adulto quanto ao acesso à educação e à cultura. Nesse caminho, o governo cubano dedica esforços e recursos para o aperfeiçoamento do trabalho dos docentes e sua formação com maior qualidade, aproximando a formação inicial e a escola, e aumentando a responsabilidade escolar e de cada professor. Com tal empenho, desenvolvem-se os estudos sobre as peculiaridades do trabalho na formação docente, a qual deve contribuir para realizar as aspirações da educação para todos.

Considerando a importância na qualidade na formação dos profissionais da pedagogia, a discussão será permeada na valorização de trabalhar os valores morais na educação infantil por meio de uma formação humanizadora visando a educação como um processo social.

\section{Os valores morais na educação infantil}

Visando a contribuir para a expansão de pesquisas a respeito da moralidade, fundamentados em nossas leituras e pesquisas, pudemos perceber a importância do tema para o desenvolvimento de crianças no início da idade escolar. Além disso, a filosofia é uma das grandes responsáveis por discutir e elaborar teorias sobre a moral na sociedade.

Há muitos anos, na história da humanidade, a constituição do homem em comunidades é um fato concreto. Os grupos humanos primitivos deram origem à sociedade, cuja formação adquiriu características cada vez mais complexas. Por sua vez, essas complexidades originaram as relações sociais, 
O curso de pedagogia em Cuba...

as quais compeliram os homens a elaborar normas valorativas e morais para determinados comportamentos em sociedade.

Pensar na sociedade e em sua forma valorativa não é fácil: os valores morais, nos dias de hoje, estão sendo esquecidos crescentemente, em razão das normas da sociedade na qual vivemos. Valores como bondade, justiça, generosidade, felicidade e amizade, entre outros, são atributos muito relevantes e que, por isso, precisam ser trabalhados ainda na infância.

Entretanto, ainda mais atualmente, há quem pergunte: "Qual é a necessidade de estudar a moral na educação?”. Para responder a essa indagação, é preciso relembrar as ideias do filósofo grego Aristóteles. De acordo com ele, as virtudes exercem um caráter valorativo para o indivíduo na sociedade; dito de outra forma: ao assumir uma virtude, o indivíduo está favorecendo a formação de sua subjetividade.

O mesmo acontece com os valores morais, se desenvolvida satisfatoriamente, resulta em aspectos positivos na formação dos indivíduos. Está comprovado que, quando atingem a vida adulta, há mais chances de desenvolverem outras virtudes, como a bondade e a cooperação. De acordo com o dicionário de Houaiss (2001), ${ }^{5}$ aos valores morais como conjunto de regras, normas de uma sociedade ou determinada região. Outros dicionários, como o "Aurélio" e o "Lexis", definem "valores morais" da mesma maneira, além de acrescentarem palavras sinônimas como: princípios, moral, preceitos, padrões, crenças, normas, regras, convicções.

Aristóteles foi um dos primeiros pensadores a refletir acerca de questões éticas na sociedade. Para ele, o agir ético não é um meio, mas um fim, e para agir eticamente é necessário que haja uma racionalidade relativa a como o ser humano interage com o mundo (ARISTÓTELES, 1992). Tal racionalidade refere-se os valores morais, ao Cristianismo e à benevolência.

Diante dos questionamentos com os quais nos deparamos e da importância social e científica de estudar os valores morais e as virtudes na

\footnotetext{
${ }^{5}$ O Grande Dicionário Houaiss da Lingua Portuguesa foi elaborado pelo lexicógrafo brasileiro Antônio Houaiss. Sua primeira edição foi lançada em 2001, no Rio de Janeiro, pelo Instituto Antônio Houaiss.
} 
Educação, conduziremos nosso estudo para a investigação sobre a maneira pela qual se dá os valores morais na Educação Infantil.

O tema "moralidade humana" é objeto de estudo há muitos anos, desde os estudos de Aristóteles até os dias atuais. Na visão aristotélica, as virtudes são constituintes do caráter humano, o qual é relacionado com a origem social do indivíduo por meio da educação transmitida pela cultura e pela sociedade na qual está inserido. Afirma o filósofo grego que as virtudes são hábitos adquiridos que conduzem os sujeitos em suas vidas. Para o sujeito tornar-se um ser virtuoso, segundo o ponto de vista aristoteliano, é necessário equilíbrio, isto é, um meio-termo, expressão utilizada nas próprias obras do mencionado pensador.

Para Aristóteles é preciso educar criando hábitos, desde o principio (Educação Infantil). Uma vida regada com a felicidade se faz conforme à educação de valores. A virtude como elemento fundamental dentro dos valores morais de acordo com Aristóteles, depende da prática desses valores morais.

Ainda para o autor, nenhum indivíduo nasce virtuoso, mas sim, construído com os ensinamentos principalmente na educação escolar (prática). Só nos tornamos justos praticando atos justos, só somos bons, praticando bons atos. Os valores morais é regada pela educação, pois ela é uma disposição de caráter que torna alguém bom e o faz agir bem.

Em meios as integrações dos conhecimentos do mundo globalizados, suas medições com as novas tecnologias, é necessários pensar na educação de valores com um aporte humanista onde, o principal objetivo é tornar uma educação consciente, voltada para os valores morais visando os pensamentos, ações os povo.

O alemão Kant (1980) deu o ponto de partida para as pesquisas atinentes à moral, ao elaborar reflexões acerca da moralidade na área da Educação. Para Kant (1980), a moralidade é composta por imperativos categóricos absolutamente necessários e não contingentes, nos quais o valor não depende das consequências dos atos, sejam externas, sejam internas; imediatas ou não. 
O curso de pedagogia em Cuba...

Em Crítica da Faculdade do Juízo, o citado filósofo alemão apresenta sua filosofia como uma análise crítica, como uma maneira de construir conhecimento que é considerada antropocentrista. 6

O homem, na perspectiva de Kant (1980), é um ser finito guiado pela razão, pela vontade e pela liberdade. Em outras palavras, o homem constitui um ente racional, que vê o mundo como algo dividido em dois polos: no primeiro (o "mundo sensivel”), os seres estão totalmente submetidos aos instintos estimulados pelo exterior; no segundo (o "mundo inteligível”), a razão prevalece na liberdade, suscitando a independência do sujeito. Finalmente, a verdadeira moral, de acordo com as concepções kantianas, é baseada no dever de agir segundo os princípios universais.

Ocupemo-nos agora de autores que dedicaram suas pesquisas aos valores morais em crianças e adolescentes. Jean Piaget (1994) e Lawrence Kohlberg (1992) são alguns dos precursores das pesquisas acerca da moralidade. Não discorreremos sobre a teoria de Kohlberg (1992), pois a pesquisa proposta intenta privilegiar as ideias piagetianas (as quais parecem mais apropriadas para o tipo de estudo que pretendemos realizar).

Piaget recorreu aos conceitos kantianos de anomia, autonomia e heteronomia, quando elaborou, por meio de pesquisas empíricas, sua teoria sobre o juízo moral na criança. O único livro escrito pelo autor sobre a moralidade foi Le jugement moral chez l' enfant, de 1932. Por meio da observação do jogo de bolinhas entre garotos e do jogo de amarelinha entre garotas, Piaget (1994) buscou mostrar, nessa obra, não os comportamentos morais infantis, mas os juízos formados por essas crianças, ainda que algumas vezes seja possivel perceber, no mencionado livro, descrições de ações e comportamentos de natureza moral nos meninos e meninas por ele observados.

A moralidade humana, é resultado dos processos vividos em nossas relações sociais e começa a ser construída desde muito cedo. As crianças,

\footnotetext{
6 "Antropocentrista" é uma das denominações dadas a um movimento que destaca o positivismo e o surgimento da ciência em seus modelos ortodoxos. A "revolução copernicana" (empreendida pelo astrônomo Copérnico), por exemplo, encaixa-se nesse processo.
} 
desde o nascimento, estão imersas em grupos sociais, com regras, normas, valores e expectativas que serão vivenciados e internalizados de forma ativa ao longo de seu desenvolvimento. A familia e a escola são grupos importantes para a construção da moralidade infantil e merecem atenção especial das pesquisas que optam por estudar o desenvolvimento do juízo moral infantil.

A consequência mais direta de não se ater à moralidade infantil é o prejuízo à construção da moralidade no adulto. Para La Taille (2009), grande parte das pesquisas sobre a moralidade revela a dificuldade de adolescentes e adultos construírem a autonomia moral, mesmo estando dentro de certos limites de idade.

As observações que fizemos a respeito da "cultura da vaidade" nos mostram um universo ainda mais problemático: o "crepúsculo do ver" aponta para uma sociedade na qual "a ação correta" consiste naquela que satisfaz instrumentalmente as necessidades próprias e, ocasionalmente, as necessidades dos outros. Relações humanas são vistas como relações de troca de um mercado. Elementos de justiça, reciprocidade, repartição igualitária estão presentes, mas não são sempre interpretadas de um modo físico, pragmático. A reciprocidade é do tipo "você coça minhas costas e eu coço as suas". (LA TAILLE, 2009, p. 17).

Em uma sociedade na qual os principios morais estão cada vez mais esquecidos, falar sobre o juízo moral não é tarefa fácil, porém necessária, uma vez que é extremamente importante a todos os aspectos da vida pessoal e social dos sujeitos.

Segundo o citado estudioso suíço, "toda moral consiste num sistema de regras, e a essência de toda moralidade deve ser procurada no respeito que o indivíduo adquire por essas regras" (PIAGET, 1994, p. 11). Dessa forma, muito mais importante é entender os processos mentais que levam a respeitar ou não determinadas regras.

A filosofia proporcionou grandes reflexões acerca da necessidade de introduzir investigações sobre o tema enfocado aqui. Observe-se, por exemplo, o que diz Bovet (1911, p. 64): “[...] les principes moraux ont, dans l'individu et dans la race, une histoire, que la psychologie de laboratoire éclaire d'une 
O curso de pedagogia em Cuba...

lumière singulièrement vive" (numa tradução aproximada feita por nós: "os princípios morais têm, no indivíduo e na raça, uma história, que a psicologia experimental explicita com uma luz singularmente brilhante").

A propósito, cabe salientarmos o valor que Piaget (1983, p. 97) deu à filosofia em sua obra Sabedoria e Ilusões da Filosofia, publicada em 1969:

A filosofia é uma retomada de posições raciocinada a relação à totalidade de real. O termo "raciocinada" opõe a filosofia às tomadas de posições puramente práticas ou afetivas ou ainda às crenças simplesmente admitidas sem elaboração reflexiva: uma pura moral, uma fé. (PIAGET, 1983, p. 97).

Para Piaget (1994), há um possivel paralelismo entre o desenvolvimento da lógica e a formação do juízo moral no sujeito. Na esteira do raciocínio piagetiano, Freitas (2002, p. 305) afirma que o desenvolvimento cognitivo acompanha pari passu a "constituição dos sentimentos".

Piaget (1994) apoiou-se na filosofia de Kant para definir as três tendências morais que, segundo ele, fazem parte do desenvolvimento do juízo moral na criança: a heteronomia e a autonomia. ${ }^{4}$

$\mathrm{Na}$ fase denominada anomia, período que vai do nascimento até por volta dos três ou quatro anos de idade, a criança ainda não tem consciência das regras, e seu agir é direcionado para a satisfação de impulsos motores ou de suas fantasias. Nesse estágio, está ausente a preocupação com regras coletivas e com as atividades em grupo.

Durante a heteronomia, propensão que dura dos 4 aos 9 anos de idade, em média, a criança já percebe a existência de regras e aparece o interesse em participar de atividades coletivas. As normas, no entanto, são concebidas por ela como algo sagrado e imutável, estabelecidas por uma entidade divina ou pela tradição, e nunca como produto de um contrato. De acordo com Piaget (1994, p. 101), a heteronomia é a “moral do dever”. 7 A prática das regras é

\footnotetext{
${ }^{7}$ A heteronomia é uma inclinação moral na qual as regras provêm dos outros, de fora do individuo, e são seguidas, sobretudo, pelo medo da punição. Durante a fase da autonomia, ao contrário, as regras são entendidas como contratos construídos entre os indivíduos e o respeito a elas parte do interior das pessoas, não sendo necessárias referências externas superiores para legitimá-las.
} 
imitativa, ou seja, a criança obedece a determinadas normas, seguindo os modelos oferecidos pelos adultos ou por companheiros mais velhos; porém, adapta-as segundo seu egocentrismo e não tem consciência do que elas significam.

Nesse periodo, as crianças julgam os atos alheios por meio do que Piaget (1994, p. 103) designou "julgamento por responsabilidade objetiva", no qual a criança leva mais em conta as consequências materiais do fato infrator do que a intenção de quem cometeu a falta.

Vê-se quanto as respostas são resistentes às sugestões contrárias tentadas por nós e quanto as crianças, se bem que compreendendo perfeitamente as histórias contadas e, por conseguinte, as intenções dos personagens em jogo nas histórias, só levam em conta, em suas avaliações, fatos materiais e não as intenções que foram a causa indireta desses fatos materiais. (PIAGET, 1994, p. 105).

Crianças com propensões predominantemente heterônomas julgam as ações alheias com muita rigidez, sugerindo punições rigorosas para aqueles que cometeram alguma falta causadora de grande prejuízo material; entretanto, não consideram a intenção dos envolvidos.

A teoria piagetiana ampliou horizontes no que concerne às questões morais no sujeito, visando à realização de pesquisas na área do desenvolvimento moral. Assim, o pensador suíço acreditava que a moral não constituía somente uma transmissão de normas e valores socialmente compartilhados, e sim uma difusão dessas regras e valores por meio de um processo de desenvolvimento moral no qual a aquisição da autonomia seria o ponto final. Um dos sucessores de Piaget, Lawrence Kohlberg, formulou uma teoria centrada na razão e que conferia grande ênfase à autonomia.

Atualmente, no Brasil, os estudos sobre a moralidade e suas virtudes se têm mostrado de grande importância para o desenvolvimento da Educação, ao propor reflexões acerca da temática sob a ótica aristotélica, isto é, pela perspectiva da virtude. Esse movimento se estabeleceu por intermédio de Yves de La Taille. Autor de várias obras, esse estudioso sempre buscou novas 
O curso de pedagogia em Cuba...

formas de pesquisar o desenvolvimento moral nas crianças, mediante a 1 dicotomia entre direitos e deveres.

La Taille desenvolveu uma nova proposta de trabalho com virtudes como gratidão, coragem, temperança e generosidade, segundo uma perspectiva prósocial. Assim é que se pretende desenvolver o estudo que propomos: Investigar como ocorre a prática dos valores morais na Educação Infantil em contextos educacionais diferentes Brasil e Cuba.

Ainda conforme La Taille (2000), o desejo relacionado à virtude vai além do simples prazer físico. Transcende-se o físico na busca da harmonia e do equilibrio dos prazeres - busca essa cuja meta fundamental é a felicidade. Nas palavras do autor: “o 'dever fazer', essencial à moral, corresponde a um querer fazer” (LA TAILLE, 2002, p.14). Nessa mesma linha, podemos pensar a dimensão ética conforme Aristóteles, para quem a ética é a busca da felicidade.

O sentimento íntimo do ser humano indica o dever moral quando não coincide com a demanda exterior, isto é, quando se trata de "querer fazer" e de "uma "vontade boa", para empregar um termo kantiano (LA TAILLE, 2006).

Piaget observava a heteronomia em crianças menores, quando elas demonstravam preocupação com um sujeito ético (o que está interligado ao desenvolvimento moral da obediência). Diante dessas implicações, La Taille (2006, p. 110), expõe o seguinte questionamento: “[...] ao compreender a moralidade, estaremos concebendo o ser humano como um 'saco de virtudes'? De modo algum. Uma teoria de 'saco de virtudes' pressupõe justaposição entre diversas virtudes".

Embora não seja o único ambiente adequado para trabalhar as virtudes, a escola é provavelmente o mais apropriado, porque é aí que os grupos sociais se formam e constituem seus valores morais e virtudes.

Quando falamos em valores morais na escola, não estamos referindonos à disciplina de Educação Moral e Cívica (já excluída, aliás, dos currículos escolares). Entre as novas estratégias para o desenvolvimento de tais valores, apontamos a transversalidade, inserida nos Parâmetros Curriculares Nacionais (BRASIL, 1997). 
Apesar de apresentar a ética como uma proposta a ser trabalhada em conjunto e em todas as matérias, não demonstra, entretanto, preocupação com os valores morais. Se acreditamos que os valores morais enriquece o campo da educação, parece-nos pertinente, então, elaborar propostas pedagógicas que possam favorecê-la (VALE, 2012).

\section{Considerações finais}

No Brasil há uma ênfase na construção social do professor como um ser social crítico e um agente transformador da sociedade. Pensar na educação como um processo social e humano caracteriza na educação de qualidade e na formação de indivíduos autônomos e críticos.

Os profissionais de pedagogia em Cuba recebem uma educação desde seu primeiro ano voltado para um ensino humanizador. Enxergam seus alunos como um processo importante para a sociedade e a educação moral como uma alternativa para estabelecer uma educação por meio das virtudes.

Trabalhar as virtudes na infância é essencial porém, dificil. Portanto, é necessário destacar a qualidade na formação desse profissional, para saber quando agir mediante uma situação de conflito e como fazer essa situação se tornar um momento rico para trabalhar as virtudes na infância.

Hoy en el mundo de globalizacion neoliberal, el problema de las crisis y degradación de los valores Morales, es resultados y causa de los problemas globales que afetam tanto a los seres humanos, como al médio ambiente. En ello la agrudización de la contradicción entre la ética del ser y la ética de tener y del todo vale, es uma amenaza real de la absorcíon de los valores identitarios y culturales de los pueblos del tercer mundoo, por las posiciones hegemónicas de uma super cultura y valores globales que los países del primer mundo tratan de imponer a toda costa y a culquier precio. (ARTEAGA, 2015, pg. 16).

Para a autora a Educação tem seu processo formativo com uma instituição social. O cognitivo, afetivo e social deve ser trabalhados com 
O curso de pedagogia em Cuba...

conjunto, levando em consideração as vivências dos alunos, seu contexto social, estabelecendo laços afetivos e respeitando os processos cognitivos de cada aluno.

A moral tem uma importante esfera para a regulamentação e autoregulação consciente de suas atitudes e do seu comportamento humano na sociedade. Pensar na importância de trabalhar os valores morais na educação infantil é ser uma educação humanizadora onde, a educação vai além dos conteúdos, passando a ser um integrador de conhecimentos e habilidades sócias.

Libâneo fez algumas considerações importantes sobre os reducionismos das novas experiências na formação de educadores.

O esfacelamento dos estudos no âmbito da ciência pedagógica, com a consequente subjunção do especialista no docente, e a improcedente identificação dos estudos pedagógicos a uma licenciatura, talvez sejam dois dos mais expressivos equívocos teóricos e operacionais da legislação e do próprio movimento da reformulação dos cursos de formação do educador, no que se refere à formação do pedagogo. (LIBÂNEO, 1991, p. 115).

Esse autor destaca a questão de "começar pelo básico" e prosseguir até o profissional. Na opinião do autor, onde há uma prática educativa com algum objetivo existirá também uma Pedagogia.

Libâneo (1991) considera a Pedagogia uma área de conhecimento relacionada com a realidade no seu contexto social. Ele considera o pedagogo um profissional que articula os fatos, as estruturas, os contextos e as situações com sua prática educativa. Assim, a relação entre a teoria e a prática tem papel fundamental para a construção da qualidade na Formação dos Professores.

A profissional da Educação deve sempre compartilhar conhecimentos considerando, a pertinência social. Trabalhar os valores morais e suas relações com o mundo globalizado tem um papel importante para conviver em uma sociedade justa.

"É necessário aplicar um enfoque ético, axiológico y humanista de forma 
sistemática e intencionada com sua forma educativa e investigação pedagógica nas diferentes áreas” (ARTEAGA, 2015, p. 54).

Desenvolver uma ética profissional tendo como base o respeito com a dignidade humana, a solidariedade, a cooperação, colaboração são fatores essenciais para trabalhar os valores morais na educação infantil.

As competências dos professores em relação ao ensino dos valores morais com relação ao conhecimento, representa a pedagogia como uma ciência onde, os aspectos sociais, afetivos e cognitivos se relacionam de uma forma unificada.

Os estudos da dimensão ética e moral é de extrema importância no mundo atual, as propostas de pesquisas tem seus objetivos centrados na formação dos profissionais de educação assim como, os sujeitos que estão em processo de formação.

Portanto, as relações entre a proposta de uma dimensão ética de qualidade na formação dos profissionais de educação, tendo como referência a educação de Cuba, segue em conexão, pensando sempre na qualidade do ensino dos valores morais na educação infantil e sua importante para a formação do humano de forma integral para a sociedade.

\section{Referências Bibliográficas}

ABED. Associação Brasileira de Educação a Distância. Relatório Analítico da Aprendizagem a Distância no Brasil, 2016. Disponivel em: <http://abed.org.br/censoead2016/Censo_EAD_2016_portugues.pdf>. Acesso em: 10 jan. 2018.

ARISTÓTELES. Ética a Nicômaco. 2. ed. Tradução M. G. Kury. Brasília: Universidade de Brasilia, 1992. (Trabalho original publicado em 384 - 322 a.c).

ARTEAGA, N. C. Educación en Valores retos y Experiencias. Havana: Acuario, 2015. 
O curso de pedagogia em Cuba...

BOVET, P. Les conditions de l' obligation de conscience. L' Année Psychologique, v. 18, 1911.

BRASIL. Conselho Nacional de Educação. Diretrizes Curriculares Nacionais para o Curso de Pedagogia, 2006. Disponivel em: <http://portal.mec.gov.br/cne/arquivos/pdf/rcp01_06.pdf>. Acesso em: 1 jan. 2017

(1996). Ministério da Educação. Lei n. 9.394. Estabelece as diretrizes e bases da educação Nacional. In: SILVA, C.S.B. da, MACHADO, L.M. (Orgs.) Nova LDB: trajetória para a cidadania? São Paulo: Arte e Ciência, p. 137-166, 1998.

CASTRO, C. de M. Escolas feias, escolas boas? Ensaio, Rio de Janeiro, v.7, n.25, p. 342- 354, out.-dez. 1999.

CUBA. Ministerio de las Relaciones Exteriores de la República de Cuba. Cuba: su historia, su cultura, su arquitectura. Havana, Cuba: MRE, 2005.

FREITAS, H. C. L. Formação de Professores na Escola Cubana: o processo nas séries iniciais. In: GOERGEN, P.; SAVIANI, D. (Orgs.) Formação de Professores: a experiência internacional sob o olhar brasileiro. Campinas, SP: Autores Associados; São Paulo: NUPES, 1998. p. 213-233.

GÓMES GUTIÉRREZ, L. I. La universalización de la educación superior pedagógica: impacto y proyecciones estratégicas sobre el sistema educacional cubano. Habana, Cuba: Ministerio de la Educación de la República de Cuba, 2006.

HOUAISS, A. Dicionário Houaiss da lingua portuguesa. Rio de Janeiro: Objetiva, 2001.

KANT, E. Fundamentação da metafísica dos costumes. In: __. Os pensadores. Tradução P. Quintela. São Paulo: Abril Cultural, 1980. v. 2. p. 101-162. (Obra original publicada em 1785).

KANT, E. Crítica da faculdade de juízo. Rio de Janeiro: Forense Universitária, 2008. (Obra original publicada em 1790) 
HERNANDEZ, M. V. (org.). Sistema Educativo Nacional de Cuba. Capitulo 1. Educación y Sociedad. 1995. Disponível em: <http://www.oei.es >. Acesso em: 20 ago. 2017.

- Sistema Educativo Nacional de Cuba. Capítulo 7. Educación Preescolar. 1995. Disponível em: <http://www.oei.es>. Acesso em: 20 ago. 2017.

KOHLBERG, L. Psicologia del desarrollo moral. Spain: Desclée de Bouwer, 1992.

LA TAILlE, Y. A importância da generosidade no início da gênese da moralidade na criança. Psicologia: Reflexão \& Crítica, Porto Alegre, v. 19, n. 1, p. 9-17, 2006. Disponivel em: <http:/ /www.scielo.br/scielo.php?script=sci_arttext\&pid=S0102$79722006000100003>$. Acesso em: 10 fev. 2014.

- Desenvolvimento humano: contribuições da psicologia moral. Psicologia USP, São Paulo, v. 18, n. 1, p. 11-36, 2007.

. Desenvolvimento moral: a polidez segundo as crianças. Cadernos de Pesquisa, São Paulo, n. 114, p. 89-119, 2001.

. Para um estudo psicológico das virtudes morais. Educação e Pesquisa, São Paulo, v. 26, n. 1, p. 109-121, 2000.

. O sentimento de vergonha e suas relações com a moralidade. Psicologia:, Reflexão e Crítica, 2002.

LIBANEO, J, C. A didática e as Tendências Pedagógicas. Série Ideias. São Paulo, FDE, 1991.

MARIÑO SÁNCHEZ, M. A.; SIERRA RICARDO, L.; LYVA SOLER, C. La Formación del profesor general integral: una experiencia de las universidades pedagógicas de Cuba. Anales del IV Congreso Internacional de Educación Superior - La universidad por un mundo mejor - Habana - Cuba, 2004.

MINED - Ministerio de Educación de Cuba, colectivo de autores de la Dirección Nacional de Primaria e Instituto Central de Ciencias Pedagógicas. 
O curso de pedagogia em Cuba...

Modelo de Escuela Primaria. Habana-Cuba, 2006.

MINED - Ministerio de Educación de Cuba, colectivo de autores de la Dirección Nacional de Secundaria Básica e Instituto Central de Ciencias Pedagógicas. Modelo de Escuela Secundaria Básica. Habana-Cuba, 2007.

OLIVEIRA, C. A. C. Geografia e ensino no Brasil e em Cuba: um estudo histórico-geográfico comparado. 2007. 267f. Tese (Doutorado em Geografia) Faculdade de Filosofia, Letras e Ciências Humanas, Universidade de São Paulo, São Paulo, 2007.

PIAGET, J. O juízo moral na criança. São Paulo: Summus, 1994. (Obra original publicada em 1932).

- Sabedoria e ilusões da filosofia São Paulo: Abril Cultural, 1983. (Coleção Os Pensadores). (Obra original publicada em 1969).

VALE, L. G.; ALENCAR, H. M. A generosidade em contraposição à obediência à autoridade: juízos morais e crianças e adolescentes. In: ROSSETTI, C. B.; ORTEGA, A. C. (Orgs.). Cognição, afetividade e moralidade: estudos a partir do referencial teórico de Jean Piaget. São Paulo: Casa do Psicólogo, 2012. p. 235-244. 